\title{
Exploring the Constructive Alignment of Pedagogical Practices in Science and Engineering Education in Sub- Saharan African Universities: A Nigerian Case Study
}

\author{
https://doi.org/10.3991/ijep.v11i2.15539 \\ David Olubiyi Obada $\left({ }^{(}\right)$ \\ Africa Center of Excellence on New Pedagogies in Engineering Education, \\ Zaria, Nigeria \\ doobada@abu.edu.ng \\ Olayinka Omowunmi Adewumi, Chika Yinka-Banjo \\ University of Lagos, Akoka, Nigeria \\ Amos Bajeh \\ University of Ilorin, Ilorin, Nigeria \\ Razak Alli-Oke \\ Elizade University, Ondo, Nigeria
}

\begin{abstract}
Improved pedagogical approaches in teaching science and engineering are crucial to solving the most pressing technological challenges faced in most developing countries especially in Sub-Saharan African Universities. Despite the avalanche of programs to train faculty members to fill this need, there is a need to conceptualize benchmarks for evaluating how teaching should be delivered to students in our institutions. The aim of this paper is to showcase how science and engineering courses can be taught in a more effective manner in our universities, with a pilot deep-dive into a few courses taught in the faculties of science and engineering in selected Nigerian Universities using the backward design approach. Five (5) case studies of undergraduate science and engineering courses were outlined and the backward design approach was used to put them into context. These case studies show how courses can be taught and assessed following three important steps. Distinct recommendations for science and engineering faculty members based on the outcome of this study are: defining clear learning objectives and outcomes, aligning assessment and evaluation methodologies, and constructively aligning all aspects of the curriculum and instructional materials. In addition, learning outcomes can be evaluated real-time in the classroom using the proposed pedagogies.
\end{abstract}

Keywords—Pedagogy; Technology: Sub-Saharan Africa; Engineering Education; Blooms' Taxonomy; Backward Design Approach 


\section{Introduction}

Notwithstanding the existence of higher science and engineering institutions in SubSaharan Africa, that are on an annual basis, graduating hundreds of students for about five decades, there has been very little moving forward in terms of the effective usage of the science and engineering concepts learnt during the various programmes for industrial development. It is a common trend that most industries in Sub-Saharan Africa rely heavily on the technological advances in terms of equipment and expertise which are delivered by more developed countries. One of the reasons why this problem persists could be ascribed to the type of teaching methods adopted by some institutions in the Africa sub-region. In this direction, there is a growing need for effective teaching pedagogies with a view to enhancing the training of our graduates to suit the industrial needs of the developing nations. To achieve these, an alignment of our teaching methods with current trends is needed. It would therefore be useful to identify a system which works and provide a framework for the desired change. This brings to the fore the concept of constructive alignment as a guidance concept.

The theory of constructive alignment [1, 18-21] simply refers to what teachers ought to do so that students can actively participate to achieve the intended learning outcomes. Figure $1(\mathrm{a} \& \mathrm{~b})$ relates to aligned and unaligned approaches as it relates to the efficient delivery of courses. The aligned course is characterized by a synergy between the teacher and students' intentions, while the unaligned course works otherwise.

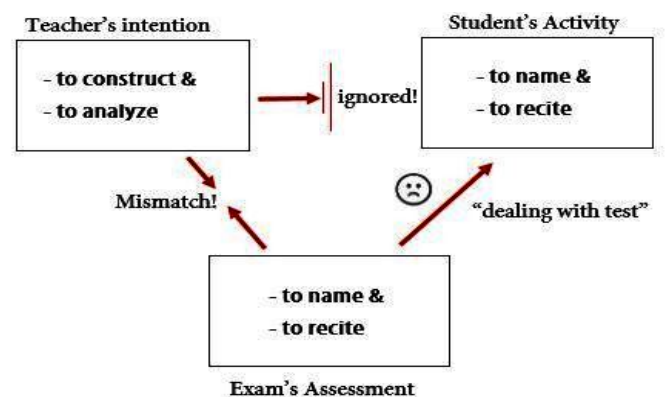

a)

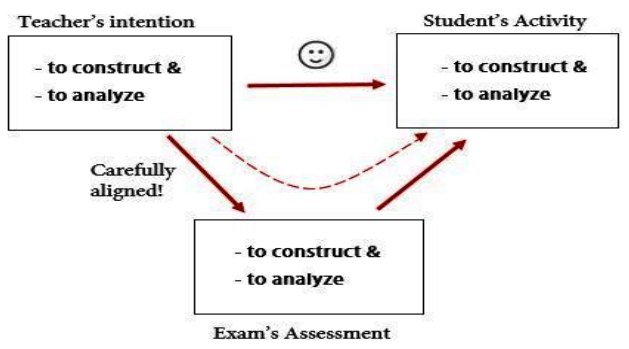

(b)

Fig. 1. A description of a) an aligned course b) an unaligned course (reproduced from Braband, [2]) 
In this way, it is important to implement a course alignment process (see Figure 2), which helps in actualizing a course alignment objective.

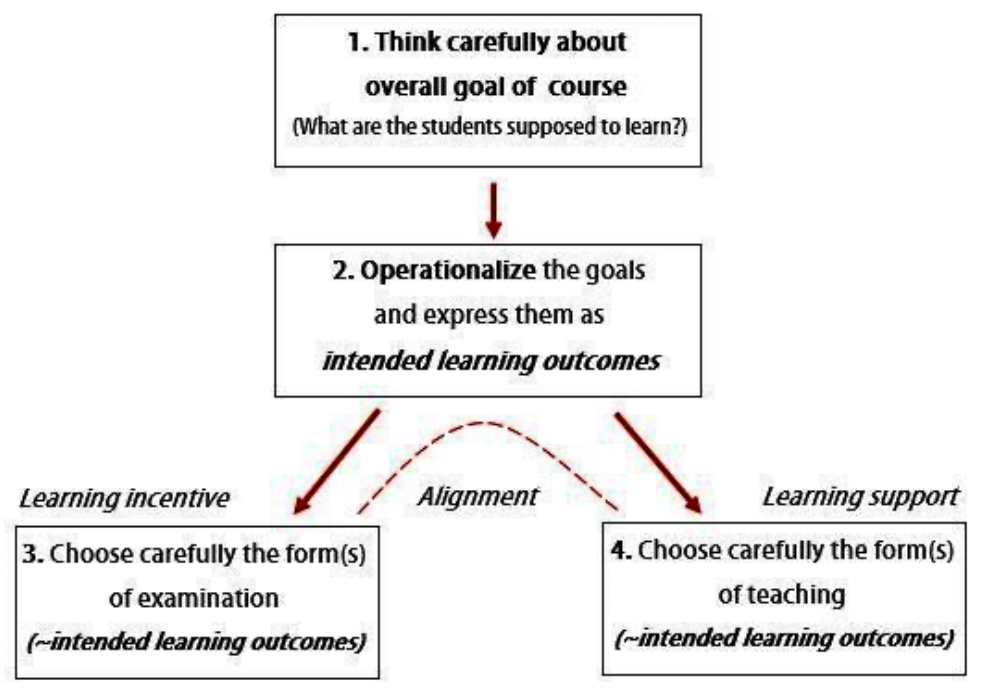

Fig. 2. Alignment implementation process (Abstracted from Braband, [2])

Bearing these in mind, globally, teachers, instructors, educational institutions including universities and polytechnics, are engrossed in a hot debate on the best pedagogical approach to prepare students for opportunities in the academia and industry which mirrors the Blooms Taxonomy [3]. However, there is a general belief that teaching methods in developing economies, for instance, Nigeria, is still hovering around the misperceptions of both knowledge and cognition. Thus, the traditional approach to teaching and learning in developing nations is still popular.

Therefore, it is important that teachers / university lecturers need to know that an optimal learning environment is important [22], coupled with advanced collaborative teaching pedagogies, a proven method [23, 24], and as a matter of priority, previous knowledge in the exact context in which learning is supposed to occur. To put this into context, Shuell [4] suggests that if students are to learn desired teaching outcomes in an effective manner, the teacher's fundamental task is to ensure that the students engage in learning activities that most likely would result in their achieving those outcomes. It is noteworthy to remember that what the student does is essentially more important in determining what is learnt than what the teacher does. In this direction, Wiggins and Mctighe [5] urged teachers to think of a backward approach which encapsulates a backward integration from the big ideas they want to inculcate, choosing teaching methods, and designing assessment tools to show if the students have achieved success. This aligns and constitutes a constructive alignment where the outcomes, assessment, teaching methods and learning experiences are symmetric, promoting enhanced learning for the students. Again, worthy of note is the fact that constructive alignment 
is a sine qua non for worthwhile learning but should not be considered a total solution [6].

\section{Theoretical Framework: The Backward Design Approach}

The backward design approach is not a new concept. As far back as 1948, Ralph Tyler articulated a similar approach in curriculum design to enhance the learning environment [7]. The framework of backward design emphasizes a process of design that starts with the identification of the desired results and then constantly reverts backwards to develop assessment criteria and the experiences that the students are supposed to be faced with. The three main steps to drive this approach are described in Figure 3. An important reward for following these three main steps is achieving what John Biggs [8] terms "constructive alignment". An alignment occurs when the desired learning outcomes are communicated to the students and the learning activities are well organized to achieve the intended outcomes.

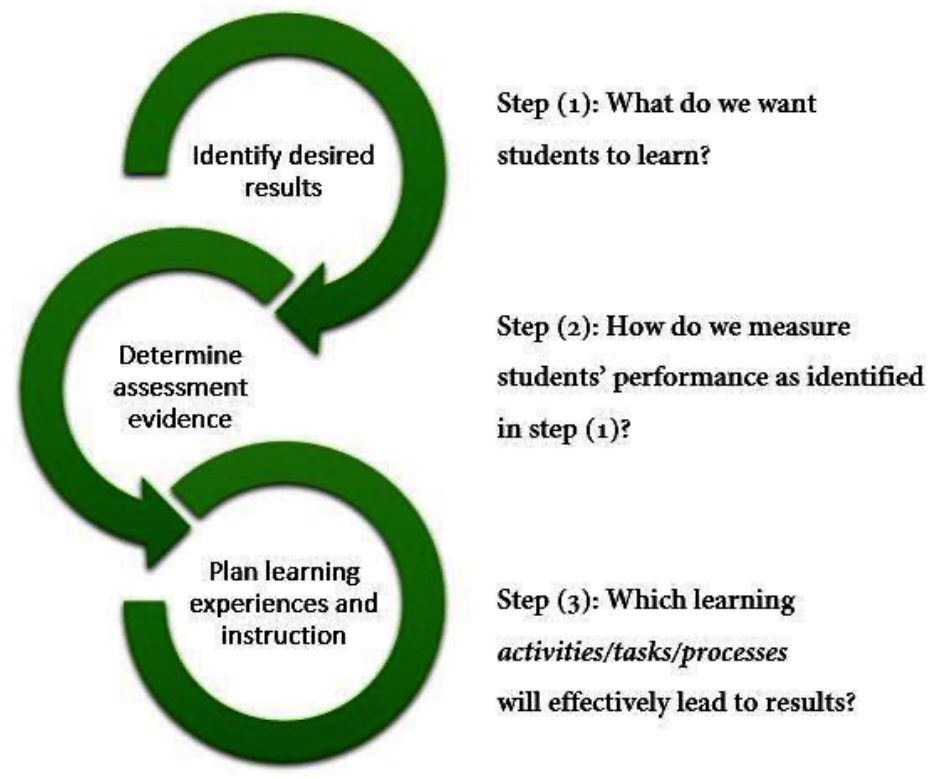

Fig. 3. The Model of Backward Design (Adapted from [9])

Some studies have been devoted to aligning course structures to achieve intended objectives using approaches that encapsulate backward design. Robert Gagne [10] and Robert Mager [14] over the years have taught on how to analyze different learning outcomes and what exactly is required of learning. Spady [11] reported the idea of "designing down" from learning outcomes [12]. However, the model of backward design is mostly linked with Wiggins and McTighe in their book captioned "Understanding by Design". Wiggins and McTighes' backward design approach is 
always associated with the Biggs' constructive alignment as mentioned earlier. The constructive alignment builds essentially on both constructive learning theories which is embedded in psychology through which learners construct their own learning and also the alignment of the curriculum with intended learning outcomes, pedagogies and assessment protocols. These tasks are all in line with the intended learning outcomes [13]. Arthur et al., [15] investigated the synergies in terms of variables between teacher and students, with a focus on students' interest in mathematics in the Ashanti region of Ghana. They found that the contribution of these predictor variables in explaining the variance in students' interest was less than $1 \%$. The study therefore suggested that teachers should make efforts in connecting mathematics to real life scenarios to help build student interest which enhances construction and analytical aptitudes. Mohammed and Ismail [16] developed a framework for the integration of goal setting skills in electrical technology education (ETE) curriculum by employing exploratory sequential design. Three elements were chosen as goal setting skills for the implementation of the ETE which included creative solution development amongst others. This can be related to allowing the students go steps further on the Bloom's taxonomy.

Contribution of the study: To analyze case studies using the backward design approach, four universities in Nigeria were selected as reference points. These selections are based on the affiliations of the authors who were selected to participate in the Massachusetts Institute of Technology-Empowering the Teachers Program (MIT-ETT, Spring2019 Cohort). Introducing the universities briefly, Ahmadu Bello University (ABU) is a Federal Government owned University in Zaria, Kaduna State Nigeria. The university runs a variety of undergraduate and graduate programmes in science and engineering. The University of Lagos is one of the most competitive in Nigeria and has one of the largest student populations of any university in the country with a wide variety of undergraduate programmes in science and engineering. The University of Ilorin, is a Federal Government owned university in Ilorin, Kwara State, Nigeria. The university is a very large co-educational higher education institution with an enrolment range of 30,000-34,999 students. Elizade University is a private university situated in Ilara-Mokin, Ondo State, Nigeria. All mentioned universities are committed to producing self-reliant, and globally competitive graduates equipped with the requisite skills, so as to be key players in the nation's quest for socio-economic and technological development. However, to consolidate on these, there is a need to review pedagogies in the classrooms.

Hence, this paper seeks to collate case studies of specific courses in science and engineering departments in some selected universities in Nigeria with a view to essentially discussing methods of course delivery which adopts the backward design approach. This has the potential of raising the bar in the type of science and engineering graduates we want to produce in Nigeria to fill the gaps identified in recruiting graduates in academia and industries for economic development. 


\section{Case Studies}

This section presents five case studies which adopts the backward design approach to how courses can be taught and assessed. The three steps according to the theoretical framework (backward design approach) were used to describe the course delivery methods. These are:

1. Identifying the intended learning outcomes

2. Determining the assessment criteria which constitutes the acceptable result of competency in the outcomes

3. Planning the strategies that bring students close to these designed levels as the accepted competency levels. This is as described by Krosslyn, [17].

Stemming from step three (3), we reckon that there are pedagogical decisions to be established at three levels before selecting specific strategies based on specific science domains. The chosen strategies have to be based on overall plans which dictate the sequencing of teaching within a particular topic. Based on the courses in the case studies, the learning outcomes fit into the framework of the selected teaching strategies to address the demands of the particular science domain under consideration. We identified four factors to guide these selections:

1. The students' background and perception across a broad range related to the subject

2. The nature and systematic flow of the intended learning outcomes

3. Analysis of the intellectual demand of the students in moving from the perception across a broad range of the subject to specific intended learning outcomes

4. A consideration of the teaching strategies that helps the students to successfully transit from existing viewpoints on the subject towards the actual scientific view

To conduct this analyses, two courses from the department of mechanical engineering as well as computer science, and a course from the department of electrical and electronics engineering are discussed using the description of the course as introduction in each sub-section.

\subsection{Fundamentals of fluid mechanics}

In the University of Lagos, Nigeria, the fundamentals of fluid mechanics course is one of the core courses undergraduate mechanical engineering students register in their second year. The intended learning outcomes (ILOs) for the course which comes from the ILO for each topic of the subject are listed in Figure 4: 
Course Title: Fundamentals of Fluid Mechanics

Intended Learning Outcomes: At the end of this course, students will be able to:

1. discuss basic concepts commonly used to investigate fluid flow

2. recall properties relevant to fluid flow analysis

3. analyze forces applied by fluids at rest

4. analyze motion of fluids without considering the forces causing the motion

5. analyze forces in fluids and write the equations of motion describing fluid flow

6. apply the equations of motion in flow measuring devices

Fig. 4. Learning Objectives for Fundamental of Fluid Mechanics

Assessment methods of the fluid mechanics course: Frequent testing helps in reinforcing what the students are learning and for this intended learning outcome, weekly problem sets (p-sets) and in-class work are chosen as assessment methods.

It is a good practice to outline the objectives of the assessment methods chosen. For example, after the students complete the problem sets and in-class work, they should be able to:

1. Accurately recall the expressions used to obtain the resultant force which liquids exert on plane and curved submerged surfaces and the point where they act

2. Apply the expression in (1) above to obtain accurate values of resultant forces and their point of action for different scenarios of practical interest

3. Understand how to use and accurately interpret tables of moments of inertia and other geometric properties of important plane surfaces.

4. Examine the solutions obtained and justify them based on their analysis of the different scenarios posed in the problem.

\section{Strategies that brings students close to the accepted competency levels}

To achieve the intended learning outcomes, the following strategies can be used

1. Evoking deep processing: In order for students to effectively discuss basic concepts commonly used to analyze fluid flow, they need to be able to identify processes around them that involve fluid flow and the classifications of fluid flow in those processes.

2. Evoking positive emotions: This strategy is closely connected to the first strategy because students need to identify processes around them and use examples of activities they enjoy doing. For example, students that enjoy watching car races, playing around with electronic devices which are cooled using fluid flows, cooking etc., will easily remember basic concepts in fluid flow if they connect them to these kinds of activities. These will get them excited about the course because they can connect it to their everyday lives. 


\subsection{Dynamics of machinery}

The dynamics of machinery course suggests that mechanical devices must move and perform their intended functions. The intended learning outcomes (ILOs) for the course which comes from the ILO for each topic are listed in Figure 5:

\section{Course Title: Dynamics of Machinery}

Intended Learning Outcomes: At the end of this course, students will be able to:

1. differentiate kinematic and kinetic motion and understand the fundamental relationship between time, distance, acceleration and velocity

2. apply vector mechanics as a requisite tool for solving problems that have to do with kinematics

3. determine the number of independent variable factors which affects the range of states in which a mechanism exist (direction in which independent motion can occur)

4. describe and utilize analytical and graphical methods to study the motion of mechanisms

5. design fundamental gear trains and cam systems

6. create a schematic drawing of a mechanism in real-time

Fig. 5. Learning Objective for Dynamics of Machinery

Assessment methods for the dynamics of machinery course: The design project and problem set are important tools in achieving the intended learning outcomes in Figure 5. The project allows the subject matter to be introduced to generate interest and activate students' prior knowledge which links the days' activities to what has come before. It allows for hands-on exploration which is conducted in small groups. For instance, asking the students to design and fabricate a simple grinding tool allows them to understand relationships between the machine elements and relates the concepts of mass, force and space.

The problem set can be used to learn and become familiar with the course notes and to solve typical problems. It can be used as part of a summative assessment of the total course module. The selected assessment techniques align well with the selected ILO in terms of allowing the students hands-on. In addition, the problem sets bring to life the ideas taught in the classroom and allow the students to conceptually solve problems that inculcates the relationship between variables like time, distance, acceleration and velocity.

Strategies that bring students close to the accepted competency levels: To achieve the intended learning outcomes, the following strategies can be used:

1. Fading from full worked example to practice problem: This strategy involves the teacher providing fully worked examples and gradually reducing fully worked examples to examples that require steps which the students have to complete. Eventually, it is expected that the worked example fades into a complete practice 
problem which the student is expected to complete from start to finish. When students or non-experts learn new concepts, it is more effective for them to study solutions of worked examples in a stepwise manner.

2. Fluent retrieval strategy: This strategy involves the students' ability to retrieve relevant knowledge from being effortful to relatively effortless, reducing the effect of cognitive loading. It is a strategy in which recalling information or principles enhance and boost learning, a practice which adapts students to pull out knowledge and examine things that they know.

3. Metacognitive strategy: This strategy refers to methods used in helping students understand the way they learn. It is designed for students to 'think' about their 'thinking'. To further elaborate, this means that rather than immediately ask the teacher for assistance, the student who has encountered any problem must consult with his or her group first. This approach has the potential to encourage the students to independently exercise control over their learning and progress, thereby making them more independent and self-directed learners.

\subsection{Introduction to operating systems}

This course is structured to explain the function of fundamental software in computer systems. The intended learning outcomes (ILOs) for the course are listed in Figure 6:

\section{Course Title: Introduction to operating systems}

Intended Learning Outcomes: At the end of this course, students will be able to:

1. understand and explain the major operating system software, subsystem managers and their functions

2. analyze basic and virtual memory management system

3. demonstrate the influence of page allocation methods on virtual mem

4. implement the different process scheduling algorithm

5. identify deadlock, starvation, how to recover and prevent their occurrence

6. identify and differentiate between processes and processors

7. understand how several processors, executing a single job, cooper

8. interpret several different network topologies - including the star, ring, bus tree, and hybrid - and how they connect numerous hosts to the net

9. evaluate the role of the operating system with regards to system

Fig. 6. Learning Objective for Introduction to Operating Systems

Assessment methods for the introduction to operating systems course: Problem sets and projects can be used to assess ILO, for instance ILO 1, and this is intended to evaluate students understanding on how to analyse basic and virtual memory in any computer system. The problem set (Pset) will enable the students to analytically apportion space to incoming jobs in the memory and make sure that every job is allocated the appropriate size without wasting the memory resources. On the other 
hand, the project will be used to reinforce the concepts the students learnt on this topic, which can be recreated by the students with real life problem solving.

Strategies that bring students close to the accepted competency levels: Each of these modules can be taught using the following strategies:

1. Presenting foundational material first: This strategy will present a backbone to the students and enable them to relate to the physical examples that will come as the class progresses.

2. Promoting chunking: In order to enable students store in memory, organizing materials into chunks promote effective learning.

3. Building on prior associations: Association of already known practices to new practices helps to drive home principles of the new practices. For instance, associating operating system to everyday software that run on the smart phones of every student in the class will put a human face to the new lecture.

\subsection{Computer programming}

The proliferation of computer devices in businesses and daily human life has made computer programming a very important skill for harnessing the power of computing devices for businesses and benefit. For developing economies to attain industrialization, sufficient and capable human capital skillful in computer programming is needed in order to meet the demand of the industries and reduce importation of software, meeting its needs and exporting software products.

The intended learning outcomes (ILOs) for the course which comes from the ILO for each topic are listed in Figure 7.

Course Title: Computer Programming using $\mathbf{C}++$

Intended Learning Outcome

At the end of this course, students will be able to:

i) describe the structure of a typical $\mathrm{C}++$ program

ii) construct valid $\mathrm{C}++$ expressions using variables, constants and operators

iii) analyze problems to break them down into procedures and classes modularization and object-orientation

iv) invoke in-built $\mathrm{C}++$ functions to perform basic tasks

v) implement user-defined functions in $\mathrm{C}++$

vi) implement classes using the concept of object-orientation

vii) design embedded programs that can drive computer hardware

Fig. 7. A Sample of Learning Objective for Computer programming in $\mathrm{C}++$

Assessment methods for the computer programming course: Some of the assessment methods applicable to computer programming courses are the use of inclass quizzes, home assignments, problem set, project and examinations. The in-class 
quizzes will involve completing a partially written code to writing a small program to accomplish a given program requirement. Home assignments and problem sets will be more tasking than the quizzes. The assignments will be a formative type of assessment that borders on one or two topics at a time. The p-sets could cover several topics with a lot of the use of abstraction (built-in and user defined functions) in solving problems. The project involves the students, usually in groups, to develop a full-fledge solution to a real-life problem, while the solution is to be turned in at the end of the course.

Strategies that brings students close to the accepted competency levels: To achieve the intended learning outcomes, the following strategies can be used:

\section{Active learning}

Active learning involves providing activities such as hands-on practices to engage the students. The teaching sessions should comprise interleaving lecturing block and activity block. The lecturing block will be used to present the programming concepts and the activity block should be used to practice coding on the computer. This strategy of actively engaging the students by making them to write or correct codes on their computer during lecture delivery will enhance their understanding of the concepts been taught.

\section{Worked examples}

Worked examples aid learning by showing the students the steps and principles taken to solve problems. The use of faded examples which progressively make the student to single-handedly solve problems, and inclusion of self-explanation questions into the examples will facilitate effective learning through worked examples. Several $\mathrm{C}++$ codes will be given to the students to enter and execute on the computer. These codes include full codes and partially written codes that will require the students to enter the remaining code to make the programs perform some predefined tasks.

\section{Demonstrate relevance}

This involves showing the students how relevant the course is to both their immediate academic courses and as a professional computer programmer. Project works in computer science often require students to design and implement software which requires them to be able to program the computer using a programming language such as $\mathrm{C} / \mathrm{C}++$. As a professional computer scientist, they are expected to know at least one powerful programming language and $\mathrm{C}++$ is one of such languages. This strategy will show the instrumental value of the course to the student thereby motivating them to learn.

\subsection{Electric circuit theory}

This is an undergraduate course taken in year 3 and it deals primarily with the analysis of electric circuits. The intended learning outcomes (ILOs) for the course which comes from the ILO for each topic are listed in Figure 8: 


\section{Course Title: Electric Circuit Theory}

Course Learning Outcomes

At the end of this course, students will be able to:

1. apply fundamental theorems and analysis techniques to electrical networks

2. analyze transient and steady-state responses of electrical circuits

3. design and build low-pass filters, high-pass filters and band-pass filters

4. synthesize and build filters networks from given transfer functions

Fig. 8. A Sample of Learning Objective for Electric Circuit Theory

Assessment methods for the electric circuit theory course: Two different assessment methods that can be used in this course are p-sets and exams. To analyze the assessment methods, this section will focus on one intended learning outcome (ILO) - Analyze steady-state responses of electrical circuits. The key concepts of this course learning objective (CLO) include steady-state response, frequency-response and application of filters.

1. P-Set: The p-set is split into three (3) exercises, with each one leading into the next exercise. Each exercise in the p-set would have about three sub-questions. The subquestions of each exercise are think-through steps for solving the main exercise question (i.e. The last sub-question).

2. Exam: The methods for exam assessment are similar to the p-set assessment techniques. Each exam question can be split into two sub-questions. Each subquestion assesses key concepts of the ILOs stated in Figure 8.

In general, the assessment methods are designed to emphasize the following techniques:

1. Formative Assessments: Giving real-time feedback to assignments and home-work. Also making available the correct solution to tests and quizzes. This strategy would let the students know where they are at and what needs to be done to be where they want to be.

2. Group Assessment: This could be in form of some laboratory activities or miniproject presentations at the end of the semester. This strategy would encourage teambuilding skills. Most real-life problems are usually tackled as a group task.

\section{Strategies that bring students close to the accepted competency levels}

1. Distribution of material and practice: This is being implemented by spacing and interleaving related topics. Topics taught in the previous class are summarily reviewed and linked to the present classes.

2. Explanatory questions and frequent quizzes: During lecture sessions, questions about a concept that has just been taught and how it relates to a plethora of studentexciting activities would be highlighted. Frequent graded/non-graded quizzes regarding what had been done in previous classes would be conducted. This would 
encourage the students to be engaged during lectures and encourage the students to master what had been taught in previous classes before attending the present class. It is important that students are engaged from time to time using questions, humour etc. as these serve as practical methods in achieving the ILOs.

\section{Conclusion}

This paper highlights improved pedagogical approaches to teaching science and engineering courses in developing nations with emphasis on selected courses in some Nigerian universities using the backward design approach. The current methods used in teaching can be improved with further emphasis on adopting the backward design approach as highlighted in the described case studies, interdisciplinary learning outcomes, which works with closer alignment of outcomes, and learning experiences. These obviously would continue to enhance the problem-solving skills of students in science and engineering education. Distinct recommendations for science and engineering faculty members are: defining clear learning objectives and outcomes, aligning assessment and evaluation methodologies with robust strategies to achieving them, and constructively aligning all aspects of the curriculum and instructional materials. Also, it is recommended that further work can be done in assessing learning outcomes, real time, in the classrooms using the proposed pedagogies.

\section{Acknowledgement}

Authors gratefully acknowledge the financial support from TOTAL, Nigeria and MISTI, Massachusetts Institute of Technology, USA for granting MIT-ETT fellowship to all authors. Authors also gratefully acknowledge the mentorship of Prof. Akintunde Ibitayo (Tayo) Akinwande of the Department of Electrical Engineering and Computer Science, Massachusetts Institute of Technology, throughout the fellowship period and beyond. The home universities are acknowledged for graciously granting leave to all the authors for the fellowship period.

\section{References}

[1] J. Biggs, "Enhancing teaching through constructive alignment", Higher education, 32(3), 347-364, 1996 https://doi.org/10.1007/bf00138871

[2] C. Brabrand, "Constructive alignment for teaching model-based design for concurrency", In Transactions on petri nets and other models of concurrency I (pp. 1-18). Springer, Berlin, Heidelberg, 2007/8. https://doi.org/10.1007/978-3-540-89287-8 1

[3] L.W Anderson, D.R Krathwohl, P.W Airasian, K.A Cruikshank, R.E Mayer, P.R Pintrich, \& M.C Wittrock, "A taxonomy for learning, teaching, and assessing: A revision of Bloom's taxonomy of educational objectives, abridged edition”, White Plains, NY: Longman, 2001

[4] T.J Shuell, "Cognitive conceptions of learning” Review of educational research, 56(4), 411436, 1986 https://doi.org/10.3102/00346543056004411 
[5] G. Wiggins, \& J. McTighe, "Understanding by design. Alexandria”, VA: ASCD. ERIC Reproduction No. ED, 424, 227, 1998

[6] L. Carter, "Five big ideas: Leading total instructional alignment", Solution Tree Press, 2009.

[7] J. McTighe \& G. Wiggins, "Understanding by Design Professional Development Workbook", Association for Supervision and Curriculum Development (ASCD), 1703

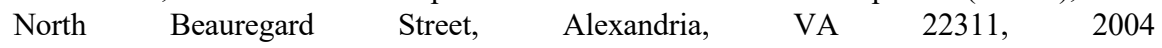
https://doi.org/10.14483/calj.v19n1.11490

[8] J. Biggs, "Enhancing teaching through constructive alignment" Higher education, 32(3), 347-364, 1996 https://doi.org/10.1007/bf00138871

[9] A. Sideeg, "Bloom's Taxonomy, Backward Design, and Vygotsky's Zone of Proximal Development in Crafting Learning Outcomes", International Journal of Linguistics, 8(2), 158-186, 2016 https://doi.org/10.5296/ijl.v8i2.9252

[10] R.M Gagne, "Analysis of objectives. In Instructional design: Principles and applications" (pp. 115-145). Educational Technologies Publications, Inc, 1977

[11] W.G Spady, "Outcome-Based Education: Critical Issues and Answers", American Association of School Administrators, 1801 North Moore Street, Arlington, VA 22209, 1994

[12] G.P Wiggins, \& J. McTighe, "The understanding by design guide to creating high-quality units" ASCD, 2011

[13] J.B Biggs, \& C. Tang, "Teaching for quality learning at university: What the student does" McGraw-hill education (UK), 2011.

[14] R.F Mager, "Att formulera undervisningsmål” Studentlitteratur, 1988

[15] Y.D Arthur, A.A Samuel, \& A. Charles, Teacher-student variables as predictor of students' interest in mathematics: The use of stepwise multiple linear regression analysis. Asian Research Journal of Mathematics, 4(3), 1-11, 2017 https://doi.org/10.9734/arjom/2017/33544

[16] D.S Mohammed, \& S. Ismail, "A Framework for Goal Setting Skills Integration in Curriculum", Advanced Science Letters, 24(5), 3693-3696, 2018 https://doi.org/10.1166/asl.2018.11467

[17] S.M Kosslyn, "The Science of Learning: Mechanisms and Principles", In S.M. Kosslyn and B. Nelson (Eds.), Building the Intentional University: Minerva and the Future of Higher Education (150-164). Cambridge, MA: MIT Press, 2017 https://doi.org/10.7551/mitpress 19780262037150.001 .0001

[18] C. Brabrand, "Constructive alignment for teaching model-based design for concurrency", In Transactions on petri nets and other models of concurrency I (pp. 1-18). Springer, Berlin, Heidelberg, 2008 https://doi.org/10.1007/978-3-540-89287-8 1

[19] X. Wang, Y. Su, S. Cheung, E. Wong, \& T. Kwong, “An exploration of Biggs' constructive alignment in course design and its impact on students' learning approaches", Assessment \& Evaluation in Higher Education, 38(4), 477-491, 2013 https://doi.org/10.1080 /02602938.2012.658018

[20] C. Loughlin, S. Lygo-Baker, \& A. Lindberg-Sand, "Reclaiming constructive alignment" European Journal of Higher Education, 1-18, 2020 https://doi.org/10.1080 121568235.2020 .1816197

[21] J. Buckley, N. Seery, L. Gumaelius, D. Canty, A. Doyle \& A. Pears, "Framing the constructive alignment of design within technology subjects in general education", International Journal of Technology and Design Education, 2020 https://doi.org/10.1007/s10798-020-09585-y 
[22] P. Appiah-Kubi, \& E. Annan, “A Review of a Collaborative Online International Learning”, International Journal of Engineering Pedagogy (iJEP), 10(1), 109-124, 2020 https://doi.org/10.3991/ijep.v10i1.11678

[23] M. Pinho Lopes and J. Macedo, "Project-based learning to promote high order thinking and problem-solving skills in geotechnical courses," International Journal of Engineering Pedagogy, vol. 4, 01/01 2014. https://doi.org/10.3991/ijep.v4i5.3535

[24] M. Moundridou, E. Zalavra, K. Papanikolaou, and A. Tripiniotis, "Collaboratively Developing Open Educational Resources for Engineering Educators in SlideWiki," International Journal of Engineering Pedagogy (iJEP), vol. 9, p. 95, 04/15 2019. https://doi.org/10.3991/ijep.v9i2.9959

\section{$7 \quad$ Authors}

Dr David O. Obada is a Lecturer at the Department of Mechanical Engineering, Ahmadu Bello University, Zaria, Nigeria. He graduated with a B. Tech in mechanical engineering at the Ladoke Akintola University of Technology, Ogbomoso- Nigeria, and obtained M.Sc. and Ph. D degrees at the Ahmadu Bello University, Zaria, Nigeria. Dr. Obada participated in the MIT-Empowering the Teachers Program at the Massachusetts Institute of Technology (MIT), USA and holds a Kaufmann Teaching Certificate also from MIT. Dr Obada currently serves as the Outreach Coordinator of the Africa Center of Excellence on New Pedagogies in Engineering Education (ACENPEE), Ahmadu Bello University, Zaria, Nigeria

Dr Olayinka O. Adewumi is currently a lecturer at the Department of Mechanical Engineering, University of Lagos, Nigeria. She received her B.Eng., M.Sc. and PhD degrees in Mechanical Engineering from the Ekiti State University, University of Lagos and University of Pretoria respectively. She is a registered engineer with the Council for the Regulation of Engineering in Nigeria (COREN) and member of the Nigerian Society of Engineers. Dr. Adewunmi participated in the MIT-Empowering the Teachers Program at the Massachusetts Institute of Technology (MIT), USA and holds a Kaufmann Teaching Certificate also from MIT.

Dr Chika O. Yinka-Banjo is a lecturer at the Department of Computer Sciences, University of Lagos (UNILAG), Akoka, Nigeria. She recieved her B.Tech. degree in Mathematics and Computer Science from Federal University of Technology Owerri (FUTO), Nigeria, her M.Sc. in Computer Science from University of Port Harcourt (UNIPORT), Nigeria, a PGD in Mathematical Sciences from University of Stellenbosch, South Africa, and a Ph.D. in Computer Science from University of Cape Town (UCT), South Africa. In addition to her teaching, research, students' supervision and several referred publications, Dr Yinka-Banjo participated in the MIT-Empowering the Teachers Program at the Massachusetts Institute of Technology (MIT), USA and holds a Kaufmann Teaching Certificate also from MIT.

Dr Amos O. Bajeh is a Lecturer at the University of Ilorin, Ilorin, Nigeria. He received his B.Sc. and M.Sc. degrees both in Computer Science at University of Ilorin in 2003 and 2009 respectively and a PhD from the Universiti Teknologi PETRONAS (UTP), Perak, Malaysia in Information Technology in 2015. Dr. Bajeh teaches several undergraduate and postgraduate courses at the University of Ilorin. Dr Bajeh 
participated in the MIT-Empowering the Teachers Program at the Massachusetts Institute of Technology (MIT), USA and holds a Kaufmann Teaching Certificate also from MIT.

Dr Razak Olusegun Alli-Oke is a lecturer in the Department of Electrical \& Computer Engineering at Elizade University, Nigeria. He received his BSc degree in Electrical \& Electronics Engineering from Obafemi Awolowo University, Ile-Ife, Nigeria in 2006. He received his MSc degree in Advanced Control \& Systems Engineering and a $\mathrm{PhD}$ degree from the Control Systems Centre, University of Manchester, United Kingdom in 2010 and 2014 respectively. Dr Alli-Oke participated in the MIT-Empowering the Teachers Program at the Massachusetts Institute of Technology (MIT), USA and holds a Kaufmann Teaching Certificate also from MIT.

Article submitted 2020-05-12. Resubmitted 2020-11-10. Final acceptance 2020-11-15. Final version published as submitted by the authors. 